\title{
Polyethylene glycol as an indigestible marker to estimate fecal output in dairy cows
}

\author{
S. Ahvenjärvi, ${ }^{* 1}$ L. Nyholm, $†$ J. Nousiainen, $†$ E. A. Mäntysaari, $\ddagger$ and M. Lidauerł \\ *Milk Production Department, Natural Resources Institute Finland (Luke), FI-31600 Jokioinen, Finland \\ †Valio Oy, PO Box 10, FI-00039 Helsinki, Finland \\ $\ddagger$ Animal Genetics Department, Natural Resources Institute Finland (Luke), FI-31600 Jokioinen, Finland
}

\section{ABSTRACT}

The objective of this study was to evaluate the accuracy of fecal output measurements using polyethylene glycol (PEG) as an external marker determined by near-infrared reflectance spectroscopy. In addition, the accuracy of dry matter intake predictions based on fecal output and digestibility estimated using an internal marker [indigestible neutral detergent fiber (iNDF)] was assessed. The experiment was conducted using 6 lactating dairy cows fed 2 different diets. Polyethylene glycol was administered twice daily into the rumen and the diurnal pattern of fecal concentrations and recovery in feces were determined. To evaluate the effects of alternative marker administration and sampling schemes on fecal output estimates, the passage kinetics of PEG in the digestive tract of dairy cows was determined and used for simulation models. The results indicate that PEG was completely recovered in feces and, thus, fecal output was accurately estimated using PEG. Good agreement between measured and predicted dry matter intake (standard error of prediction $=0.86 \mathrm{~kg} / \mathrm{d}, \mathrm{R}^{2}=$ 0.81 ) indicates good potential to determine feed intake using PEG in combination with iNDF. The precision of cow-specific digestibility estimates based on iNDF was unsatisfactory, but for a group of cows iNDF provided an accurate estimate of dry matter digestibility. The current study indicated that, to overcome inherent day-to-day variation in feed intake and fecal output, the minimum of 4 fecal spot samples should be collected over $4 \mathrm{~d}$. Preferably, these samples should be distributed evenly over the 12 -h marker administration interval to compensate for the circadian variation in fecal PEG concentrations.

Key words: polyethylene glycol, dairy cow, digestibility, feed intake

Received June 15, 2017.

Accepted January 18, 2018

${ }^{1}$ Corresponding author: seppo.ahvenjarvi@luke.fi

\section{INTRODUCTION}

Daily feed intake is an essential part of feed efficiency measurements in dairy herds, but direct measurements are difficult to carry out without specific equipment. Thus far, such equipment has been available only on dedicated research farms. If DMI of individual animals cannot be measured directly, it must be estimated using indirect methods. Several indirect techniques to estimate DMI have been proposed and evaluated (Holloway et al., 1981; Lippke 2002; Decruyenaere et al., 2012). Attempts have been made to establish relationships between fecal components, DMI, and DM digestibility (Holloway et al., 1981) or estimate fecal output and DM digestibility using a combination of internal and external markers (Kotb and Luckey, 1972; Mayes et al., 1986; Lippke, 2002). Fecal output is closely related to DMI because it is the product of DMI and DM digestibility. Fecal output can be estimated using external markers that are administered to an animal either continuously or at frequent intervals to ensure uniform distribution of markers in feces. Nonuniform distribution necessitates frequent collection of fecal grab samples to overcome diurnal variation in marker excretion pattern. If DM digestibility is known or can be determined by reference to an internal marker, then feed intake can be estimated from fecal output. Alternatively fecal output could be used as a proxy measurement for DMI within a group of animals consuming the same diet. Assuming only a small variation in digestibility between animals, fecal output is highly correlated with feed intake. Quantitatively, the differences between diets in OM digestibility can be considerably larger than those between animals. Kuoppala et al. (2010) reported 0.06unit difference in $\mathrm{OM}$ digestibility between diets based on early- or late-harvested grass silages. In contrast, Mehtiö et al. (2016) estimated a coefficient of variation of 0.017 in $\mathrm{OM}$ digestibility between individuals fed the same diet. In addition to effects on digestibility, diets have substantial effects on DMI (Kuoppala et al., 2010). 
Several external markers have been introduced and applied in digestibility studies with ruminants. Chromium sesquioxide has been the most widely used external marker since early 1950s (Kane et al., 1950), but a water-soluble compound, polyethylene glycol (PEG), proposed for ruminants by Sperber et al. (1953) has gained recent interest since the introduction of improved analytical methodology (Landau et al., 2002). Earlier PEG utilization was hampered by the lack of simple and accurate analytical techniques, but near infrared reflectance spectroscopy (NIRS) appears to provide substantial improvements to obsolete techniques. Recent studies have demonstrated that PEG concentrations can be accurately determined using NIRS (Landau et al., 2002; Hassoun et al., 2013; Casasús and Albanell, 2014). If PEG concentrations in feces can be accurately determined using NIRS, it could be used in large-scale studies to estimate fecal output; however, as a soluble compound, PEG associates with the liquid phase of rumen digesta. Rumen liquid has considerably higher passage rate than rumen particles and, as a consequence, soluble compounds exhibit higher diurnal variation in fecal concentrations than insoluble substances. A rapid passage rate entails technical challenges in achieving uniform marker distribution in feces (i.e., small diurnal variation in fecal marker concentrations). If marker is uniformly distributed in feces, only a few spot samples need to be collected to attain reliable estimates of fecal output. These problems associated with soluble markers could be alleviated by increasing the frequency of marker administration or increasing the number of fecal spot samples. However, increased frequencies of marker administration or sample collection tend to decrease the benefits provided by the cost effective NIRS analysis of PEG.

The objective of the current study was to evaluate the accuracy of fecal DM output measurements in lactating dairy cows using PEG as an external marker determined by NIRS. In addition, the accuracy of DMI predictions based on fecal output and digestibility using internal marker was assessed. To evaluate the effects of alternative marker administration and sampling schemes on fecal DM output estimates, the passage kinetics of PEG in the digestive tract was determined.

\section{MATERIALS AND METHODS}

\section{Animals, Diets, and Experimental Design}

Six multiparous Nordic Red dairy cows equipped with 10-cm i.d. rumen cannulas (Bar Diamond, Inc., Parma, ID) were used as experimental animals, in compliance with the Finnish Act on the Use of Animals for Experimental Purposes (2013). The experimental procedures were approved by the National Animal Experiment Board. Cows were, on average, 105 DIM (SD 70.1) and weighed $698 \mathrm{~kg}$ (SD 63.0) at the beginning and $735 \mathrm{~kg}$ (SD 90.7) at the end of the experiment. Cows were housed in a tiestall barn with continuous access to water and salt blocks. They were milked twice daily at 0700 and $1645 \mathrm{~h}$. The diet was offered 4 times daily at $0545,0900,1600$, and $1900 \mathrm{~h}$, according to appetite, allowing at least $5 \%$ for the refusals that were collected daily shortly before the first morning meal.

The experiment consisted of 3 periods that lasted for 26, 26, and $11 \mathrm{~d}$, respectively. Two different diets were fed to introduce responses in terms of feed intake and fecal output and to assess the diet effects on marker behavior. To allocate these diets to cows on periods 1 and 2 , animals were divided into 2 groups of 3 cows. In period 1 , the first group was offered TMR that consisted of (on DM basis) $40 \%$ of concentrates (TMR-40) whereas the second group received TMR that consisted of $60 \%$ of concentrates (TMR-60). The diets were switched between groups at the beginning of period 2. Polyethylene glycol was administered twice daily into the rumen and the circadian pattern of fecal excretion and recovery in feces were determined. In period 3, cows remained on the same diet as on period 2 and PEG passage kinetics in the digestive tract were determined based on a single dose of PEG administered into the rumen and excretion pattern of PEG determined in feces.

The forage component of TMR consisted of grass silage that was prepared from a primary growth of sward mainly comprised of timothy (Phleum pratense) and meadow fescue (Festuca pratensis). Concentrate mixture consisted (g/kg of DM) of barley (270), oats (250), molassed sugar beet pulp (250), solvent-extracted rapeseed meal (210), and mineral premix (20; Mahti Mira, Hiven Oy, Paimio, Finland). Chemical composition of grass silage, concentrate mixture, and experimental diets is presented in Table 1.

\section{NIRS Calibration}

For NIRS calibration, 66 fecal samples with determined PEG concentrations were prepared. In period 1, feces were collected on d 11 from each animal before the start of PEG administration. Between 0 to $4 \mathrm{~g}$ of PEG 6000 (average molecular weight 5,000-7,000, Merck KGaA, Darmstadt, Germany) was first dissolved in 25 $\mathrm{mL}$ of hot water in glass beakers, then mixed with 250 $\mathrm{g}$ of fresh feces on a metal tray lined with plastic foil. The beaker was rinsed with hot water to transfer PEG quantitatively to feces. The mixture of PEG and feces 
Table 1. Chemical composition of feed ingredients

\begin{tabular}{lcccc}
\hline Item & Grass silage $^{1}$ & Concentrate mixture & TMR- $40^{2}$ & ${\text { TMR- } 60^{3}}^{3}$ \\
\hline DM, g/kg & 220 & 892 & & \\
Composition, g/kg of DM & & & & \\
OM & 922 & 936 & NA & NA \\
Digestible OM & & $\mathrm{NA}^{5}$ & 24.2 & 24.6 \\
N & 681 & 25.6 & 419 & 371 \\
NDF & 23.4 & 267 & 71 & 72 \\
iNDF $^{6}$ & 509 & 75 & 348 & 298 \\
pdNDF $^{7}$ & 68 & 192 & \\
\hline
\end{tabular}

${ }^{1}$ Fermentation quality: $\mathrm{pH} 4.3$; in DM, g/kg: lactic acid 52, formic acid 15, acetic acid 43, propionic acid 1.5, butyric acid 0.6 , ethanol 38, water-soluble carbohydrates 11 ; in total N, g/kg: soluble N 575, ammonium-N 78.

${ }^{2}$ Total mixed ration consisting of $40 \%$ of concentrates.

${ }^{3}$ Total mixed ration consisting of $60 \%$ of concentrates.

${ }^{4}$ Concentration of digestible OM based on cellulase solubility in vitro (Huhtanen et al., 2006b).

${ }^{5}$ Not analyzed.

${ }^{6}$ Indigestible NDF determined based on 12-d in situ incubation in the rumen (Ahvenjärvi et al., 2006).

${ }^{7}$ Potentially digestible NDF determined as NDF - iNDF.

was dried at $60^{\circ} \mathrm{C}$ for $48 \mathrm{~h}$, weighed, and ground using a cutter mill with 1-mm screen aperture size. Polyethylene glycol concentrations were determined based on the amount of PEG added onto feces divided by the weight of dry feces and PEG after oven-drying.

\section{Sampling Procedures}

Periods 1 and 2. The first $14 \mathrm{~d}$ were allocated for adaptation to new diets and, in period 2, also to ensure removal of PEG from the digestive tract before the start of PEG administration. From d 15 until the end of each period, $300 \mathrm{~g} / \mathrm{d}$ of PEG was administered into the rumen. The daily amount of PEG was divided into two 150-g doses that were dissolved in $500 \mathrm{~mL}$ of tap water and delivered into the rumen via the rumen cannula at 0600 and $1800 \mathrm{~h}$.

To estimate the time required for PEG to approach constant levels in feces and to optimize sampling hours in the experimental design, PEG kinetics in the digestive tract of dairy cows were simulated using the data from our previous study (L. Nyholm and S. Ahvenjärvi, unpublished observations) and the compartmental model described below. These simulations indicated that PEG concentrations in feces approach constant daily averages in less than $3 \mathrm{~d}$. To examine the circadian pattern of PEG excretion in feces and to determine the time required to reach constant daily averages in fecal PEG concentrations, fecal spot samples of $500 \mathrm{~mL}$ were collected from the rectum on d 15 to 21 at $0600,1200,1800$, and $2400 \mathrm{~h}$. To characterize the diurnal pattern in fecal PEG concentrations once the equilibrium in PEG intake and fecal output had been reached, fecal samples of $500 \mathrm{~mL}$ were collected from the rectum at 0600,1000 , and $1400 \mathrm{~h}$ on d 22 . On d 23 to 25 , these sampling times were delayed by $1 \mathrm{~h}$ each day to obtain in total 12 samples that represented the entire 12-h period between PEG doses administered into the rumen.

To determine daily fecal DM output, total collection of feces conducted over $4 \mathrm{~d}$, starting on d 22 at $1800 \mathrm{~h}$ and ending on d 26 at $1800 \mathrm{~h}$ of each period. To facilitate complete recovery of feces, the floor was covered by rubber mats and feces were collected from the mats into plastic containers that were changed every $12 \mathrm{~h}$. Urine was separated from feces by means of collection harnesses attached around cow's vulva and drained into containers residing below the floor level. Feces collected over $12 \mathrm{~h}$ were weighed, mixed, and a subsample of $4 \%$ was obtained. Fecal subsamples were frozen at $-20^{\circ} \mathrm{C}$ and pooled for each cow over the 4-d collection period. At the end of periods 1 and 2, pooled feces were thawed, mixed, and subsamples were obtained for determination of DM and for the chemical analysis. To determine the chemical composition of feed ingredients and experimental diets, samples were collected from grass silage and concentrates on d 21 to 25 on periods 1 and 2.

Period 3. The first $6 \mathrm{~d}$ were allocated for complete washout of PEG from the digestive tract. On $\mathrm{d} 7$, at $0600 \mathrm{~h}$, a 300-g pulse dose of PEG was administered into the rumen. This amount of marker was predicted to give rise to maximum fecal PEG concentrations between 50 to $100 \mathrm{~g} / \mathrm{kg}$ of DM. To establish the passage kinetics of PEG in the digestive tract of dairy cows, fecal samples were obtained at $0,4,6,8,10,12,14,16$, $18,20,22,24,30,36,42,48,60,72,84$, and $96 \mathrm{~h}$ after the dose. If a cow defecated within $30 \mathrm{~min}$ of a predetermined sampling time, a sample was collected from voided feces; otherwise samples were obtained from the rectum according to the protocol. In each case, the true sampling time was recorded. 


\section{Preparation of Samples for the Analysis}

For chemical analysis, feed and fecal samples were dried in a forced-air oven at $60^{\circ} \mathrm{C}$ for $20 \mathrm{~h}$ and milled using a cutter mill equipped with a $1-\mathrm{mm}$ screen. To prepare fresh grass silage samples for chemical analysis, $20 \mathrm{~g}$ of silage was first chopped coarsely and then combined with $280 \mathrm{~g}$ of deionized water and homogenized in a blender for $3 \mathrm{~min}$. The suspension was then chilled for $30 \mathrm{~min}$ at $-18^{\circ} \mathrm{C}$ and homogenized again for $3 \mathrm{~min}$. Chilling and homogenization were repeated once more and the suspension was filtered and then centrifuged for $10 \mathrm{~min}$ at $1,831 \times g$ at ambient temperature. Samples from the supernatant were submitted to the analysis of VFA, lactic acid, formic acid, ethanol, water-soluble carbohydrates, soluble N, and ammonia N concentrations as well as measurement of $\mathrm{pH}$.

\section{Chemical Analysis}

Residual DM concentration of dried and ground samples was determined in a forced-air oven at $105^{\circ} \mathrm{C}$ for $16 \mathrm{~h}$. Silage DM concentration was corrected for the loss of volatile compounds as described by Huida et al. (1986). Ash concentration was determined in a muffle furnace according to AOAC method 942.05 (AOAC International, 2012). Nitrogen concentration in feed samples was determined using a Dumas-type elemental N analyzer (Leco FP-428, Leco Corporation, St. Joseph, MI). The NDF concentration was analyzed in the presence of $\mathrm{Na}_{2} \mathrm{SO}_{3}$, as described by Van Soest et al. (1991), using an Ankom 220 Fiber Analyzer (Ankom Technology, Macedon, NY). Heat-stable $\alpha$-amylase was used for starch containing samples. Indigestible NDF (iNDF) in feeds and feces was determined based on $12-\mathrm{d}$ in situ incubations in the rumen of dairy cows as described by Ahvenjärvi et al. (2006). Grass silage OM digestibility was determined based on pepsin-cellulase OM solubility as described by Nousiainen et al. (2003) and modified by Huhtanen et al. (2006b). Volatile fatty acid concentration in grass silage was determined by GC as described by Huhtanen et al. (1998). Milk samples were analyzed for DM, protein, fat, and lactose concentration using an infrared milk analyzer (MilkoScan 133B, Foss Electric, Hillerød, Denmark).

\section{Calculations}

Daily fecal DM output was estimated based on daily dose of PEG administered into the rumen and PEG concentration in feces obtained by the total collection method:

$$
\begin{gathered}
\text { Estimated fecal output }(\mathrm{kg} \text { of } \mathrm{DM} / \mathrm{d})= \\
\text { PEG dose }(\mathrm{g} / \mathrm{d}) / \text { PEG in feces }(\mathrm{g} / \mathrm{kg} \text { of } \mathrm{DM}) \text {. }
\end{gathered}
$$

Dry matter digestibility was calculated based on fecal output measured by total collection or estimated by PEG and daily DMI:

$$
\begin{gathered}
\text { DM digestibility }= \\
1-[\text { Fecal output }(\mathrm{kg} / \mathrm{d}) / \mathrm{DMI}(\mathrm{kg} / \mathrm{d})] .
\end{gathered}
$$

Alternatively, DM digestibility can be estimated based on internal marker concentrations in feed and feces. In the current study iNDF was used as an internal marker:

$$
\begin{gathered}
\text { Estimated DM digestibility }=1-[\text { iNDF in feed } \\
(\mathrm{g} / \mathrm{kg} \text { of } \mathrm{DM}) / \mathrm{iNDF} \text { in feces }(\mathrm{g} / \mathrm{kg} \text { of } \mathrm{DM})]
\end{gathered}
$$

Daily DMI was estimated based on fecal output using PEG and iNDF concentrations in feed and feces:

$$
\begin{aligned}
& \text { Estimated DMI }(\mathrm{kg} / \mathrm{d})=\text { Fecal output }(\mathrm{kg} / \mathrm{d}) / \\
& {[\text { iNDF in feed }(\mathrm{g} / \mathrm{kg} \text { of DM }) / \text { iNDF in feces }} \\
& (\mathrm{g} / \mathrm{kg} \text { of DM })] .
\end{aligned}
$$

\section{Statistical Analysis and Simulations}

Statistical analysis was carried out using PROC MIXED of SAS 9.2 software (SAS Institute Inc., Cary, $\mathrm{NC}$ ). The effect of diet on feed intake, fecal output, and digestibility was evaluated using the model $\mathrm{Y}=$ $\mu+\mathrm{Ai}+\mathrm{Pj}+\mathrm{Dk}+\varepsilon \mathrm{ijkl}$, where $\mu$ represents the overall mean; A represents the random effect of animal; $\mathrm{P}$ and $\mathrm{D}$ represent the fixed effects of period and diet, respectively; and eijkl represents residual variation. The coefficient of variation between days in DMI and fecal output and the coefficient of variation within-day in fecal PEG concentrations were estimated using the GLM procedure and the model $\mathrm{Y}=\mu+\mathrm{Ai}+\mathrm{Pj}+\mathrm{Dk}$ $+\mathrm{Ai} \times \mathrm{Pj} \times \mathrm{Dk}+\mathrm{Tl}+$ eijklm, where $\mu$ represents the overall mean; A, P, and D represent the fixed effects of animal, period, and diet, respectively; $\mathrm{Ai} \times \mathrm{Pj} \times$ Dk represents the interaction between animal, period, and diet, respectively; $\mathrm{Tl}$ represents the day within a balance period or hour within a day; and eijklm represents residual variation. The coefficient of variation was calculated as the root means square estimated for the day or hour divided by the mean for all observations. The same model was used to evaluate differences between animals in DM digestibility determined by total collection, PEG, and iNDF. To evaluate the accuracy 
Table 2. Diet effects on DMI, fecal output, and digestibility

\begin{tabular}{lcccc}
\hline Item & TMR-40 & TMR-60 & SEM & $P$-value \\
\hline DMI, kg/d & 15.63 & 11.64 & 0.409 & $<0.01$ \\
$\quad$ Silage & 9.28 & 15.51 & 0.322 & $<0.01$ \\
Concentrates & 24.91 & 27.15 & 0.716 & $<0.01$ \\
$\quad$ Total & 7.75 & & & \\
Fecal DM output, kg/d & 7.67 & 8.35 & 0.243 & $<0.01$ \\
$\quad$ Measured & & & 0.198 & 0.01 \\
Estimated with PEG $^{3}$ & 0.689 & 0.693 & 0.0039 & 0.16 \\
DM digestibility, kg/kg & 0.692 & 0.692 & 0.0044 & 0.95 \\
Measured $^{3}$ & 0.699 & 0.676 & 0.0074 & 0.01 \\
Estimated with PEG $_{\text {Estimated with iNDF }}^{5}$ & 1.01 & 1.00 & 0.020 & 0.54 \\
PEG recovery, g/g & 1.04 & 0.95 & 0.018 & 0.02 \\
iNDF recovery, g/g & & & & \\
\hline
\end{tabular}

\footnotetext{
${ }^{1}$ Total mixed ration consisting of $40 \%$ of concentrates.

${ }^{2}$ Total mixed ration consisting of $60 \%$ of concentrates.

${ }^{3}$ Measured by total collection of feces.

${ }^{4} \mathrm{PEG}=$ polyethylene glycol.

${ }^{5}$ Indigestible NDF determined by 12-d in situ incubation in the rumen (Ahvenjärvi et al., 2006).
}

of estimated DMI, standard error of prediction (SEP) was estimated as the square root of sum of squared differences between measured and estimated DMI.

To describe the passage kinetics of PEG entering feces, a 2-compartment model with 2 age-independent compartments (G1G1) or with a gamma age-dependent and an age-independent compartment (GnG1, $\mathrm{n}=$ 2 to 4) were used to estimate time delay (TD) and compartmental mean retention time (CMRT) in the digestive tract (Pond et al., 1988). In this model, TD was assumed to represent the retention time in the nonmixing compartments and CMRT was attributed to the residence in age dependent (CMRT1) and age independent (CMRT2) mixing compartments. The model parameter estimates were derived using SAS 9.3 software (SAS Institute Inc.) as described by Moore et al. (1992). The best model was selected based on the smallest sums of squared differences between observed and predicted marker excretion patterns. The effect of PEG administration interval on fecal pattern of marker excretion was simulated using Powersim version 2.5 software (Powersim AS, Isdalst $\varnothing$, Norway) and the 2-compartment model described above (Pond et al., 1988). Simulations were carried out using the mean parameter values estimated for PEG and assuming constant rate of fecal excretion.

\section{RESULTS}

\section{Marker Recovery}

Polyethylene glycol concentrations in the calibration standards ranged between 9 to $118 \mathrm{~g} / \mathrm{kg}$ of DM. In feces obtained by total collection and pooled over $4 \mathrm{~d}$, PEG concentrations ranged between 34 and $44 \mathrm{~g} / \mathrm{kg}$ of DM (mean $37.6 \mathrm{~g} / \mathrm{kg}$ of DM). The daily amount of PEG administered into the rumen was $300 \mathrm{~g} / \mathrm{d}$, whereas, on average, $302 \mathrm{~g} / \mathrm{d}$ (SD 14.4) of PEG was recovered in feces. No difference between diets in PEG recovery was observed (Table 2). The recovery of iNDF in feces was complete when averaged across the diets (0.99; SD $0.063)$, but the recovery was significantly higher for TMR-40 as compared with TMR-60 diet (Table 2).

\section{Fecal Output and Digestibility}

Measured fecal DM output increased significantly as a response to inclusion of higher proportion of concentrates in the diet (Table 2). On both diets, fecal DM output estimated using PEG was in good agreement with that measured by total collection. In addition, the difference between diets in fecal DM output was similar when measured by total collection $(0.69 \mathrm{~kg} / \mathrm{d})$ or when estimated by PEG $(0.60 \mathrm{~kg} / \mathrm{d})$. We found no differences between diets in DM digestibility measured by total collection or that estimated using PEG (Table 2), but that estimated using iNDF decreased significantly $(P$ $=0.01)$ as the proportion of concentrates in the diet increased. This effect seemed to be associated with a 0.09-unit difference in iNDF recovery between diets.

The diet effects on fecal output and DM digestibility were accurately estimated using PEG, but the relationship between fecal DM output estimated using PEG and measured by total collection (Figure 1) indicated observational errors in both methods $(\mathrm{SEP}=0.38 \mathrm{~kg} / \mathrm{d}$, $\left.\mathrm{R}^{2}=0.64\right)$. The coefficient of variation between days on the 4-d collection period was 0.037 for DMI and 0.055 for measured fecal DM output. These observations in- 
dicated notable day-to-day variation in feed intake, but in fecal output the daily variation was greater.

\section{Feed Intake Predictions}

Considering the low DM concentration of grass silage, it was well preserved, as evidenced by the low concentration of total fermentation acids $(98 \mathrm{~g} / \mathrm{kg}$ of DM; SD 0.6), low proportion of ammonia $\mathrm{N}$ of total $\mathrm{N}$ $(78 \mathrm{~g} / \mathrm{kg}$ of $\mathrm{N})$, and high proportion of lactic acid of total fermentation acids (0.53; SD 0.047). In terms of digestible $\mathrm{OM}$ concentration $(681 \mathrm{~g} / \mathrm{kg}$ of $\mathrm{DM})$, grass silage was of medium quality.

Daily DMI measured in periods 1 and 2 over $5 \mathrm{~d}$ before the beginning of PEG administration was not different from that measured over the period between 7 to $11 \mathrm{~d}$ after the beginning of PEG administration (26.3 vs. $26.0 \mathrm{~kg} / \mathrm{d} ; P=0.50)$. As compared with the TMR40 diet, inclusion of a higher proportion of concentrates in TMR increased feed intake (Table 2). Total DMI increased by $2.2 \mathrm{~kg} / \mathrm{d}$ as the proportion of concentrates increased from 0.40 to 0.60 of ration DM.

A consistent relationship between fecal DM output measured using total collection method and DMI indicated that DMI could be estimated directly from fecal DM output with reasonable accuracy $(\mathrm{SEP}=0.80 \mathrm{~kg} / \mathrm{d}$, $\mathrm{R}^{2}=0.83$; Figure 2 ). The accuracy of DMI estimated from fecal DM output using PEG was only marginally lower than the accuracy of DMI estimated from measured fecal DM output $\left(\mathrm{SEP}=0.85 \mathrm{~kg} / \mathrm{d}, \mathrm{R}^{2}=\right.$ 0.81 , data not shown). The accuracy of estimated DMI was expected to further improve when cow-specific digestibilities were included in DMI estimates. However, contrary to these expectations, cow-specific digestibilities derived using iNDF decreased the accuracy of DMI estimates $\left(\mathrm{SEP}=1.96 \mathrm{~kg} / \mathrm{d}, \mathrm{R}^{2}=0.34\right.$; Figure 3a). A better approach was to estimate DMI assuming the same digestibility determined for the entire group of animals using iNDF. Using the same digestibility for all cows (0.691, Table 2) rather than cow-specific digestibilities, the relationship between measured and estimated DMI was more consistent and the accuracy was improved ( $\mathrm{SEP}=0.86 \mathrm{~kg} / \mathrm{d}, \mathrm{R}^{2}=0.81$; Figure $3 \mathrm{~b}$ ).

When determined by the total collection of feces, differences between individual cows in DM digestibility were significant $(P=0.02)$, albeit very small, as the range in DM digestibility between animals was only 0.02 units. When DM digestibilities were estimated using PEG, no differences were observed between cows $(P=0.33)$ and the correlation between PEG and total collection was poor $(\mathrm{R}=-0.12)$. The correlation between DM digestibility measured by total collection for individual cows and that estimated using iNDF was

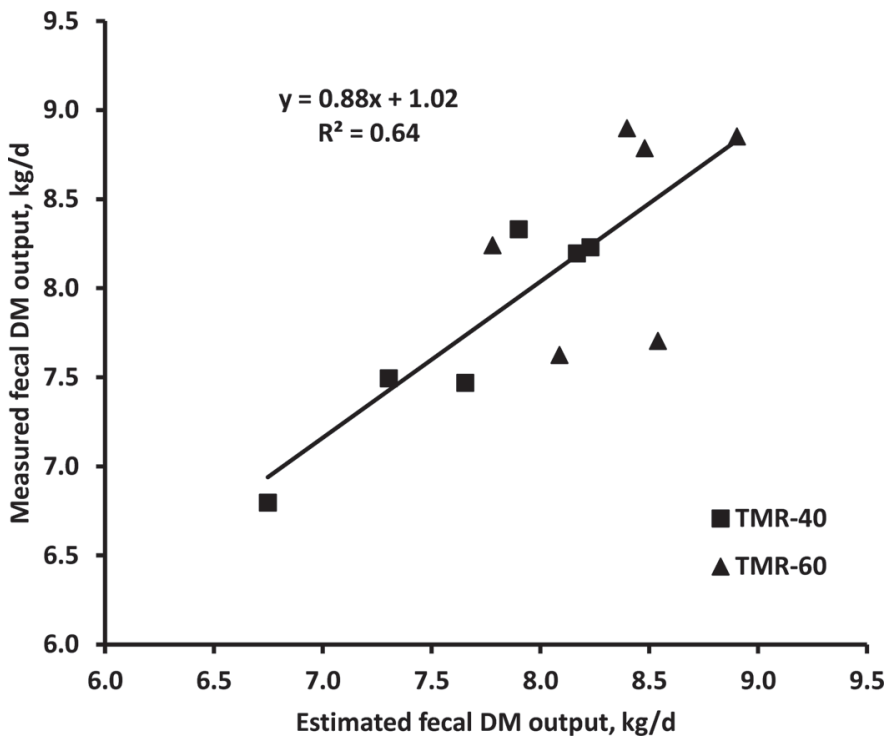

Figure 1. The relationship between fecal DM output estimated using polyethylene glycol or measured by total collection. Standard error of prediction was $0.38 \mathrm{~kg} / \mathrm{d}$. TMR- $40=$ total mixed ration consisting of $40 \%$ concentrates; TMR-60 $=$ total mixed ration consisting of $60 \%$ concentrates.

somewhat greater (0.44). As indicated by standard error of the means, the precision of total collection method was better $(\mathrm{SEM}=0.0028)$ than that of PEG $(\mathrm{SEM}=0.0067)$ or $\mathrm{iNDF}(\mathrm{SEM}=0.0068)$.

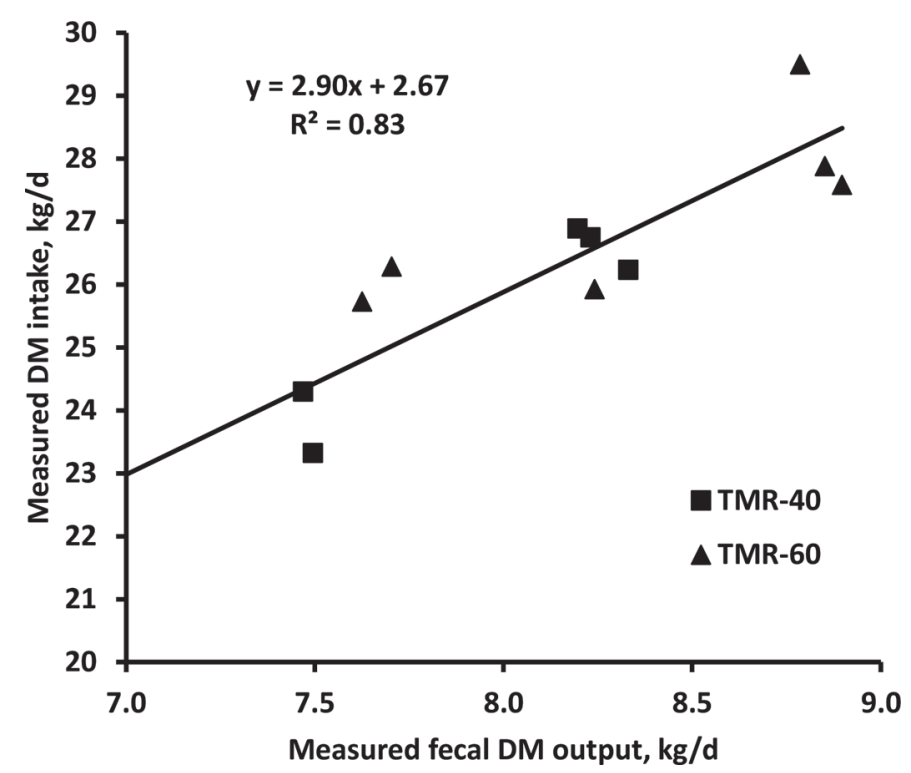

Figure 2. The relationship between measured fecal DM output and measured DMI. Standard error of prediction was $0.80 \mathrm{~kg} / \mathrm{d}$. TMR-40 $=$ total mixed ration consisting of $40 \%$ concentrates; TMR- $60=$ total mixed ration consisting of $60 \%$ concentrates. 

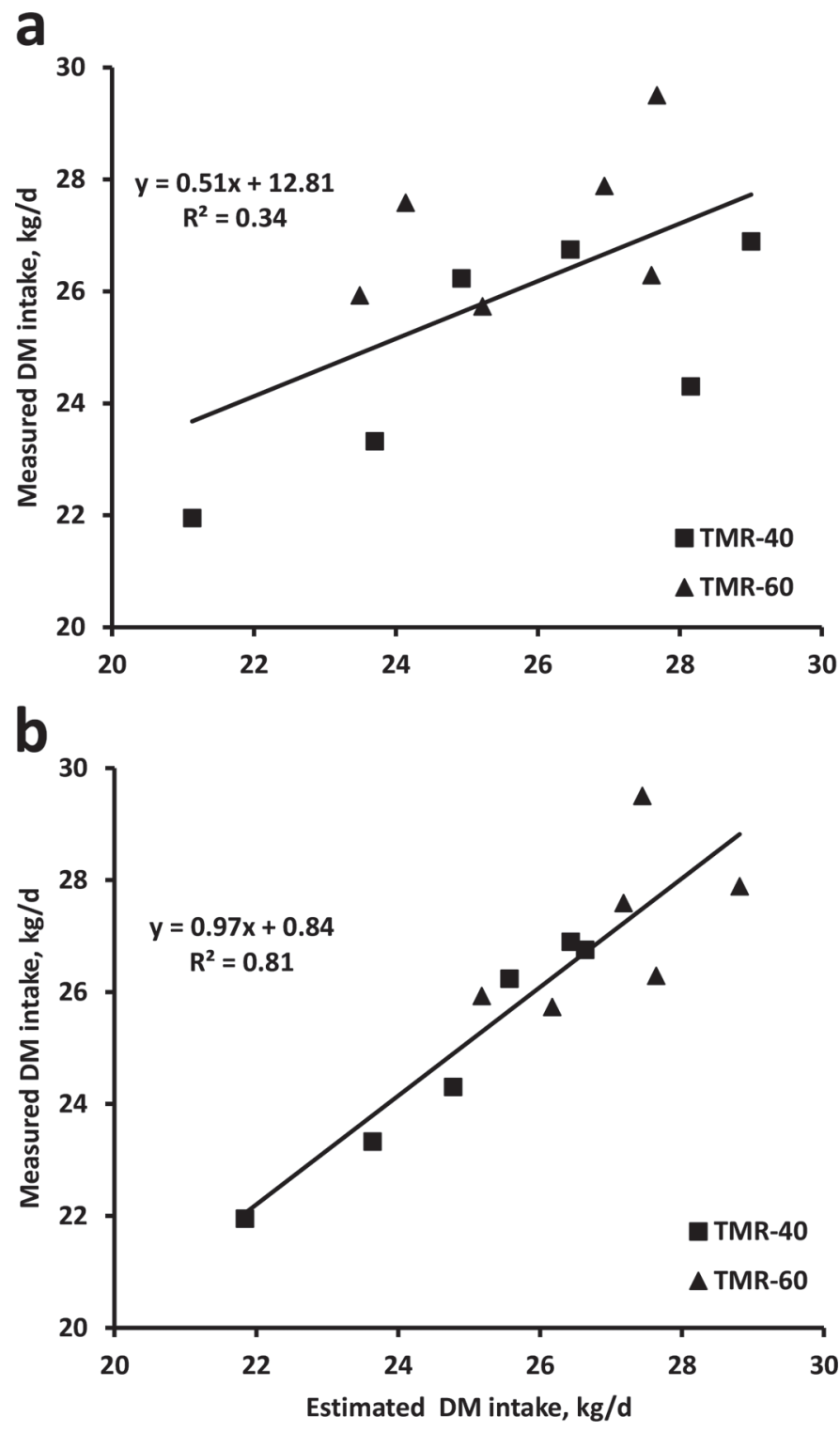

Figure 3. The relationship between measured DMI and that predicted based on fecal output estimated using polyethylene glycol (PEG) and individual (a) or averaged (b) DM digestibility (0.691) derived using indigestible NDF. Standard error of prediction was 1.96 and $0.86 \mathrm{~kg} / \mathrm{d}$ for estimates based on individual and averaged digestibilities, respectively. TMR-40 $=$ total mixed ration consisting of $40 \%$ concentrates; TMR-60 = total mixed ration consisting of $60 \%$ concentrates.

\section{PEG Passage Kinetics}

Polyethylene glycol concentrations in feces did not reach constant levels but exhibited a circadian pattern, with 6 -h intervals between the maximum and minimum concentrations (Figure 4). This pattern reflected the combined effect of 12-h administration interval and rapid passage rate of PEG from the rumen. Despite the circadian pattern of marker excretion in feces, daily means of PEG concentrations reached constant levels on the second day of marker administration (Figure 4).

The diurnal pattern of PEG excretion is presented in Figure 5. Excretion pattern was broadly similar for both diets, albeit the minimum concentrations occurred $2 \mathrm{~h}$ earlier, at $1000 \mathrm{~h}$, on diet TMR-60 compared with $1200 \mathrm{~h}$ on diet TMR-40. The maximum concentrations were observed at $1500 \mathrm{~h}$ on both diets (Figure 5). The minimum and maximum concentrations were 65 and $132 \%$ of the daily mean for TMR-40 and 70 and $134 \%$ for TMR-60 diet, respectively.

Polyethylene glycol passage kinetics in the digestive tract of dairy cows are presented in Figure 6. Differences between diets were significant only for the total mean retention time $(P=0.03,14.3$ vs. $16.9 \mathrm{~h}$ for TMR-40 and TMR-60, respectively); therefore, the results in Figure 6 and Table 3 have been presented as a mean of 2 diets and 6 animals. Polyethylene glycol concentrations started to increase at around $6 \mathrm{~h}$ after the pulse dose and reached the peak at approximately $12 \mathrm{~h}$. Thereafter, the PEG concentrations declined rapidly, and at $24 \mathrm{~h}$ were only $20 \%$ of the maximum. Compartmental analysis of marker excretion patterns indicated that the best fit was attained using the model G2G1 (Table 3). Using this model, the CMRT was, on average, $9.4 \mathrm{~h}$ and TD $6.2 \mathrm{~h}$, which was similar to the first appearance of marker in feces (Figure 6).

\section{Alternative Sampling and Marker Administration Schemes}

Collection of 12 fecal samples over $4 \mathrm{~d}$ during the daytime hours between 0600 and $1700 \mathrm{~h}$ resulted in mean PEG concentrations that were $101 \%$ of the mean concentration obtained by total collection. To assess the effects of less-frequent sampling on fecal PEG concentrations, sampling schemes based on either 4 or 3 spot samples per animal were examined. Collection of 4 samples at 3-h intervals, starting either at 0600, 0700, or $0800 \mathrm{~h}$, resulted in PEG concentrations that were 100, 100, and $103 \%$ of PEG concentrations attained using total collection, respectively. These results suggest that 4 spot samples collected at evenly distributed intervals would have been a sufficient sampling scheme in the current study. Collection of only 3 samples at $4-\mathrm{h}$ intervals, starting either at 0600, 0700, 0800, or 0900 $\mathrm{h}$, resulted in PEG concentrations that were 97, 108, 101, and 98\% of PEG concentrations attained using total collection, respectively. These results demonstrate a substantial increase in variation of marker concentrations as compared with the sampling protocols that involved 4 spot samples.

The effects of PEG administration protocols on the marker excretion patterns in feces were simulated us- 


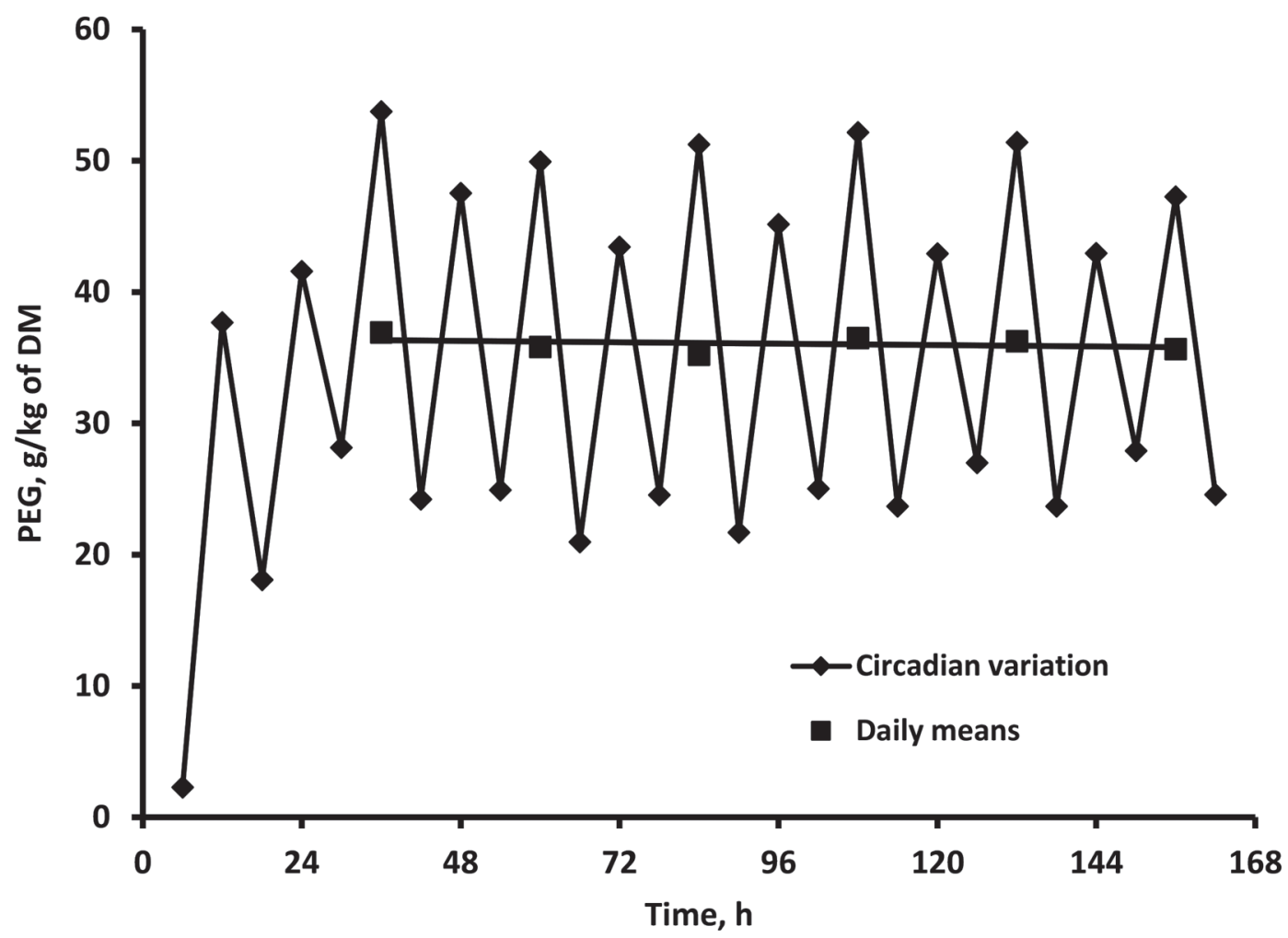

Figure 4. Circadian variation and calculated daily means in fecal polyethylene glycol (PEG) concentrations between 12 and $168 \mathrm{~h}$ after the beginning of PEG administration into the rumen; PEG was administered twice daily at 0600 and $1800 \mathrm{~h}$ into the rumen.

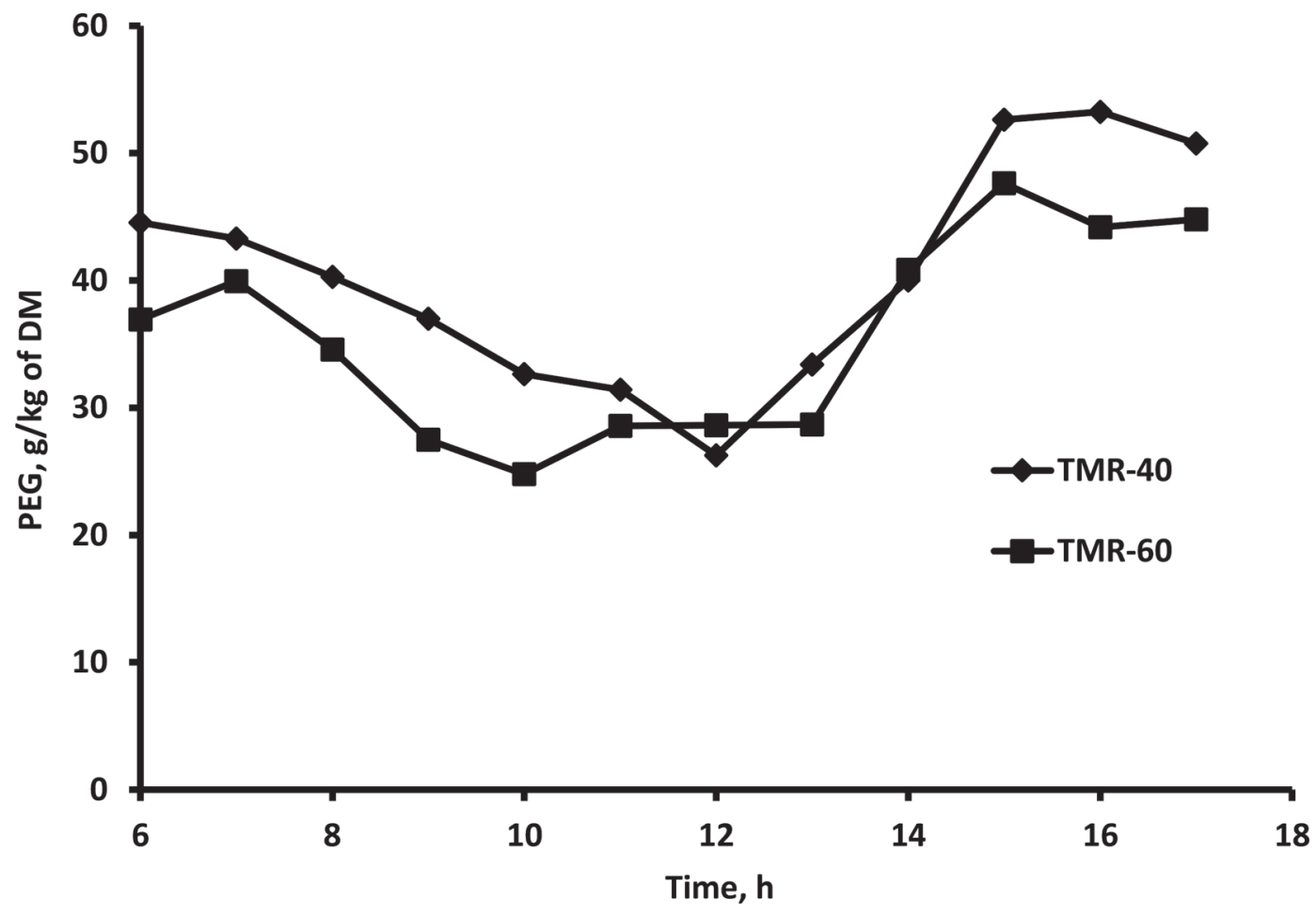

Figure 5. Diurnal pattern in fecal polyethylene glycol (PEG) concentrations for TMR consisting of $40 \%$ (TMR-40) or $60 \%$ concentrates (TMR-60) based on total collection on d 22 to 25. 


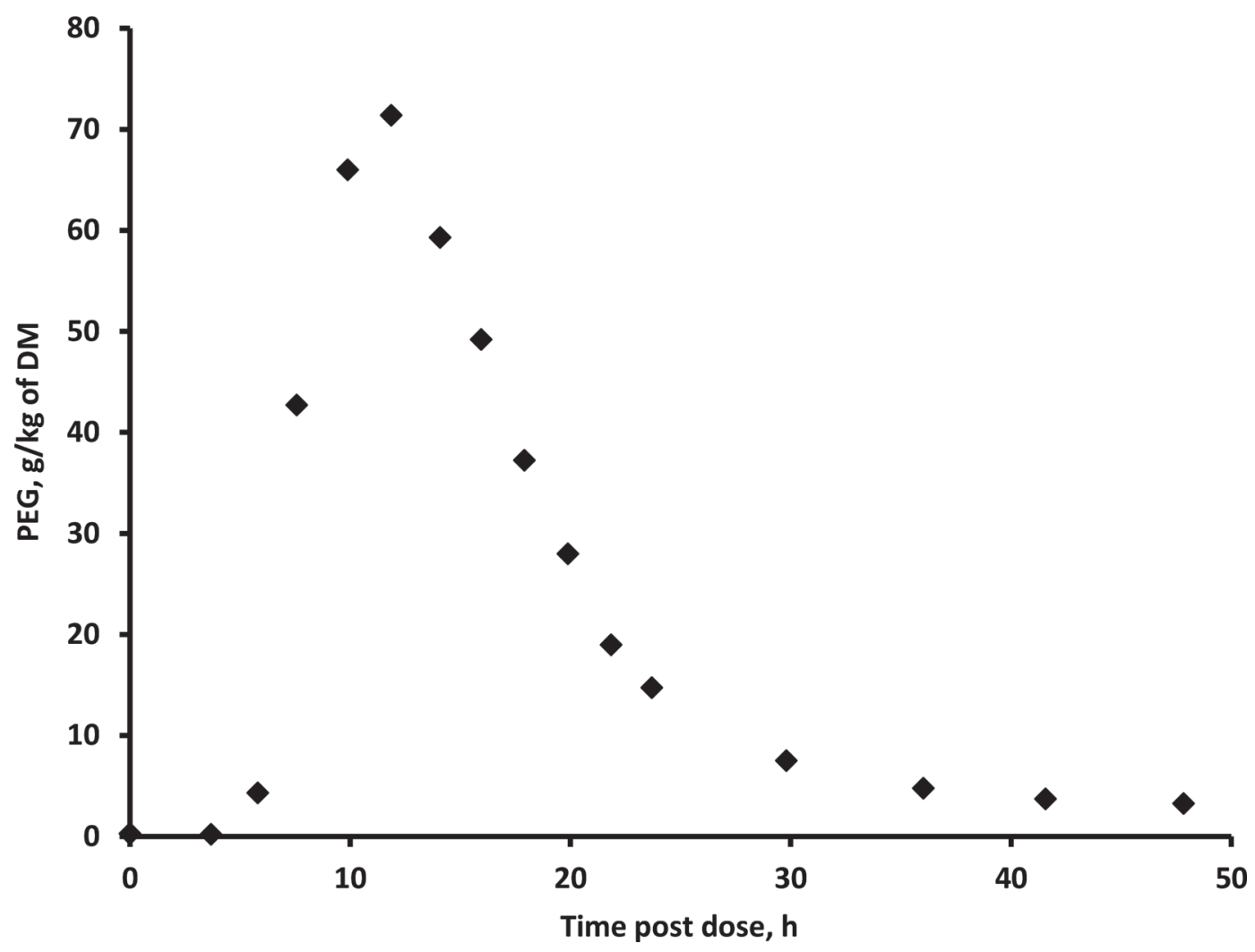

Figure 6. Fecal excretion pattern of polyethylene glycol (PEG) administered as a single dose into the rumen. The figure represents the mean of 2 diets and 6 cows.

ing the 2-compartment model (G2G1) described above and the mean parameter estimates derived for PEG (Figure 7). Therefore, the results represent 2 diets and 6 animals used in the current study. Dosing the marker at 24-h intervals resulted in large variation in PEG concentrations that ranged between 8 to $77 \mathrm{~g} / \mathrm{kg}$

Table 3. Estimated parameter values for 2-compartment models describing polyethylene glycol passage rate

\begin{tabular}{cllllcl}
\hline Model $^{1}$ & TD $^{2}$ & CMRT1 $^{3}$ & CMRT2 $^{4}$ & CMRT $^{5}$ & TMRT $^{6}$ & SS $^{7}$ \\
\hline G1G1 & 7.3 & 1.9 & 6.6 & 8.5 & 15.8 & 419 \\
Mean & 1.81 & 1.21 & 1.57 & 0.86 & 2.11 & 660.3 \\
SD & & & & & & \\
G2G1 & 6.2 & 2.6 & 6.8 & 9.4 & 15.6 & 119 \\
Mean & 1.42 & 1.42 & 1.08 & 1.14 & 1.67 & 48.7 \\
SD & 5.8 & 2.9 & 7.0 & 9.9 & 15.7 & 122 \\
G3G1 & 1.37 & 1.45 & 0.96 & 1.31 & 1.68 & 43.3 \\
Mean & 5.4 & 3.2 & 7.2 & 10.3 & 15.8 & 127 \\
SD & 1.35 & 1.56 & 0.92 & 1.46 & 1.67 & 41.7 \\
G4G1 & Mean & & & & & \\
SD & & & & & & \\
\hline
\end{tabular}

${ }^{1}$ Two-compartment models comprised either 2 age-independent compartments (G1G1) or a gamma age-dependent and an age-independent compartment (GnG1, $\mathrm{n}=2$ to 4 ) as described by Pond et al. (1988).

${ }^{2}$ Time delay attributed to passage through nonmixing compartments in the digestive tract.

${ }^{3}$ Compartmental mean retention time in the first compartment.

${ }^{4}$ Compartmental mean retention time in the second compartment.

${ }^{5} \mathrm{CMRT}=\mathrm{CMRT} 1+\mathrm{CMRT} 2$.

${ }^{6}$ Total mean retention time, TMRT $=$ CMRT + TD.

${ }^{7}$ Sum of squared differences between predicted and observed pattern of polyethylene glycol excretion in feces. ${ }^{8}$ Standard deviation between cows, $\mathrm{n}=6$. 


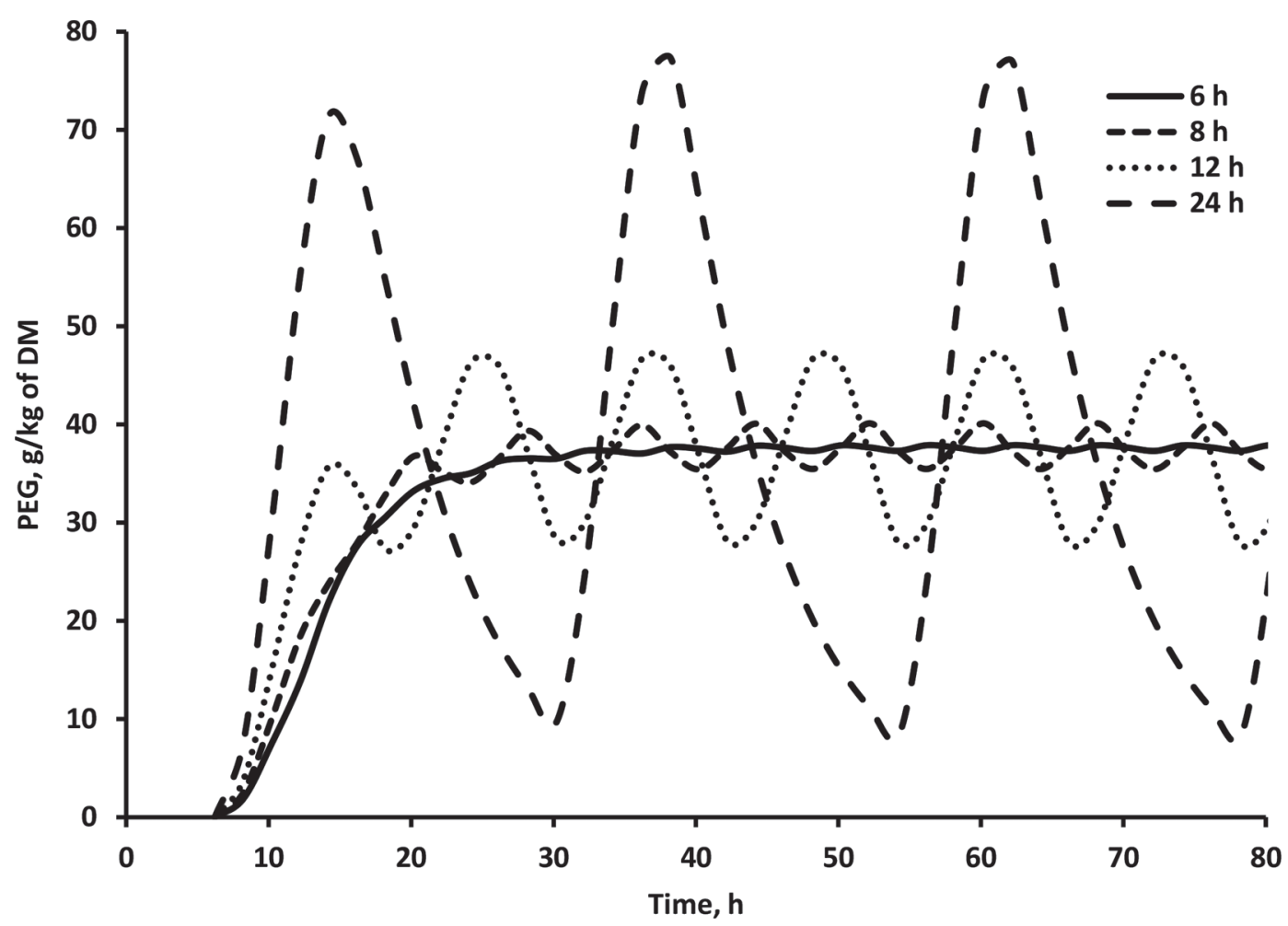

Figure 7. The effect of polyethylene glycol (PEG) dosing interval on marker excretion pattern in feces. The daily amount of PEG (300 g) was divided into several doses (4, 3, or 2 per day) or only a single dose was administered into the rumen at 6-, 8-, 12-, or 24-h intervals, respectively.

of DM. The coefficient of variation within-day in fecal PEG concentrations was 1.57. Decreasing the marker administration interval to $12 \mathrm{~h}$ decreased the range in simulated PEG concentrations between 28 to $47 \mathrm{~g} / \mathrm{kg}$ $\mathrm{DM}$ and the coefficient of variation within-day to 0.48 . The simulated range of PEG concentrations was slightly smaller than the range of fecal PEG concentrations observed in the current study (between 27 to $50 \mathrm{~g} /$ $\mathrm{kg}$ of DM and the CV within-day of 0.74 ). Decreasing the dose interval to $8 \mathrm{~h}$ further decreased the variation in PEG concentrations (35 to $40 \mathrm{~g} / \mathrm{kg}$ DM and CV within-day of 0.11). Marker administration at 6-h intervals resulted in less than $1 \mathrm{~g} / \mathrm{kg}$ of DM in differences between the minimum and maximum concentrations and the coefficient of variation within-day was 0.016 .

\section{DISCUSSION}

\section{Estimated Fecal Output}

Accuracy of fecal output estimates is primarily dependent on fecal recovery of a marker and representative sampling of feces. Incomplete marker recovery produces overestimates of fecal output and large diurnal variation in fecal marker concentrations requires frequent sample collection to obtain representative fe- cal composition. In an ideal case marker is uniformly distributed in feces (i.e., marker concentrations exhibit small variation around the daily means). In such cases, only a few spot samples are needed to account for the inherent variation between days in fecal DM output; however, complete marker recovery should not be assumed but must be ascertained in every case (i.e., in every laboratory and with each marker). Lack of digestibility and absorption from the digestive tract, as well as accurate analysis of marker concentrations, are essential prerequisites for a complete marker recovery (Kotb and Luckey, 1972).

In the current study, PEG was completely recovered in feces but the recovery rates reported in previous studies have been highly variable. Hopson and McCroskey (1972) investigated the effects of dose level on PEG recovery in steers and observed decreases in PEG recovery from 0.99 to 0.78 as the PEG dose increased from 50 to $200 \mathrm{~g} / \mathrm{d}$. Those authors speculated that incomplete recoveries at higher levels of PEG dose were potentially explained by greater losses during drenching the marker to the animals. In contrast to these findings, Andueza et al. (2013) reported increases from 0.30 to 0.78 in PEG recovery in adult wethers as the daily dose increased from 2.5 to $15 \mathrm{~g} / \mathrm{kg}$ of daily DMI. Those authors proposed the formation of complexes 
between PEG and condensed tannins as an explanation for these effects, because the formation of such complexes would have greater effects on PEG recovery at low compared with high levels (Andueza et al., 2013). Hassoun et al. (2013) reported recoveries between 0.95 and 1.09 in adult ewes fed dry feed ingredients but a lower recovery on a diet based on fresh forages (0.88). Those authors attributed low recoveries to low PEG levels $(10 \mathrm{~g} / \mathrm{d})$ and the type of diet fed to the animals. Casasús and Albanell (2014) reported an incomplete PEG recovery in dry dairy cows (0.96).

To be indigestible, elements and substances must be chemically resistant to enzymatic catabolism and of sufficient molecular size that prevents passive transfer from the digestive tract (Bjarnason et al., 1995; Arrieta et al., 2006). Low-molecular weight PEG 400 has been widely used in human studies to investigate gut permeability (Bjarnason et al., 1995), but higher-molecular weight PEG $(>3,000)$ is not transferred from the digestive tract and is excreted completely in feces (Shaffer and Critchfield, 1947; Hopson and McCroskey, 1972; Landau et al., 2002). As discussed, lack of absorption is a prerequisite but not a guarantee for complete PEG recovery in feces because incomplete recoveries may arise from several sources. The reasons for incomplete recovery have not always been evident but may be related to issues arising from inadequate NIRS calibration, inaccurate PEG administration into the animals (Hopson and McCroskey, 1972), or the fact that PEG may form complexes with condensed tannins that are contained in many feed ingredients or common weeds such as dandelion (Andueza et al., 2013).

Ruminants that have free access to feed invariably exhibit variation between days in feed intake and fecal output. In the current study, the coefficient of variation between days in feed intake (0.04) was lower than that (0.08 to 0.13$)$ reported by Casasús et al. (2004). To overcome the inherent day-to-day variation in the animal's eating pattern, accurate estimates of DMI for an individual animal can be attained only by measuring feed intake over several days. In previous studies, the length of total fecal collection period has varied between 3 to 7 d (Prigge et al., 1981; Landau et al., 2002; Casasús and Albanell, 2014). If DMI is predicted based on fecal marker concentrations, spot samples must be obtained over several days to account for the variation between days in marker concentrations. Optimal sampling hours are probably dependent on experimental conditions, because the observations of Landau et al. (2002) in goats and Hassoun et al. (2013) in sheep indicated that fixed sampling hours could be used to determine fecal PEG concentrations.

The current study indicated that fecal spot samples should be collected at different hours of the day to minimize the effects of variable fecal output and nonuniform marker distribution in feces. Our observations also indicated that, when using PEG as a marker in lactating dairy cows, a minimum of 4 spot samples should be collected to achieve similar PEG concentrations as obtained by total collection of feces. A preferred sampling scheme is to collect fecal samples over 4 consecutive days and distribute hours evenly over the 12-h interval of marker administration. In cases where samples can be collected only at fixed hours of the day (e.g., at milking parlor), then a higher frequency of marker administration is required to ensure more uniform marker distribution in feces.

\section{PEG Kinetics and Diurnal Variation}

In the current study, the range of PEG concentrations in feces varied between 0.76 and 1.33 of the daily mean, which is broadly similar to that (0.61 to 1.49$)$ reported by Casasús and Albanell (2014). In their study, dry dairy cows received a single dose of PEG (175 to $235 \mathrm{~g} / \mathrm{d}$ ) at 24 -h intervals, whereas 12 -h intervals were used in the current study. The reason for similar variation despite large differences in marker administration frequency can be attributed to large differences in DMI levels between these studies. In the study of Casasús and Albanell (2014), cows had markedly lower DMI than in the current study (9.1 vs. $26.0 \mathrm{~kg} / \mathrm{d}$ or 73 vs. $189 \mathrm{~g} / \mathrm{kg}$ of metabolic BW). Previous studies have substantiated that increases in DMI decrease the retention time of digesta in ruminants (Colucci et al., 1982; Huhtanen and Kukkonen, 1995). In dairy cows, increases in DMI from 12 to $42 \mathrm{~g}$ of $\mathrm{DM} / \mathrm{kg}$ of BW decreased the retention time of forage particles by 26 and $36 \%$ on low- and high-forage diets, respectively (Colucci et al., 1982). In dairy bulls, CMRT of liquid-associated marker (Co-EDTA) decreased by $29 \%$ and CMRT of particle associated marker (Cr-mordanted hay) decreased by $31 \%$ as a response to higher DMI (40 vs. $80 \mathrm{~g}$ of DM/ $\mathrm{kg}$ of metabolic BW; Huhtanen and Kukkonen, 1995). Therefore, within-day variation in PEG concentrations increase with increasing levels of DMI.

Despite substantial within-day variation in PEG concentrations, Casasús and Albanell (2014) concluded that pooling the fecal samples obtained at 4-h intervals over $24 \mathrm{~h}$ provided PEG concentrations similar to those obtained by the total collection method. Consistent with these findings, in the current study pooling 4 fecal samples collected at 4-h intervals during daytime hours resulted in similar PEG concentrations as attained by total collection. These observations support the view that large variations in marker concentration arising from infrequent PEG administration can be overcome by collecting several fecal samples at regular intervals. 
Liquid-associated markers, such as PEG, have considerably shorter mean retention time in the gastrointestinal tract than particle-associated markers (Snyder et al., 1984; Huhtanen and Kukkonen, 1995). Such a property has direct consequences on the diurnal variation of PEG concentrations in feces. Corbett et al. (1958) mixed chromium sesquioxide and PEG with grass cubes and administered markers to lactating dairy cows twice daily. Fecal PEG concentrations exhibited diurnal variation that was 5 times greater than that of chromium (Corbett et al., 1958). Once administered into the rumen, liquid-associated markers flow out of the reticulorumen approximating to the first-order passage kinetics (Huhtanen and Kukkonen, 1995; Krämer et al., 2013). When a marker passes through the postruminal mixing compartments (i.e., omasum, abomasum, cecum, and rectum), the slope of the ascending part of marker excretion curve (i.e., between the first appearance and the maximum concentration in feces) decreases compared with a case in which marker flows in a laminar manner through these segments. This mechanism was demonstrated by Huhtanen et al. (2006a) using simulated data and 2-compartment models with increasing gamma agedependency in one compartment (Pond et al., 1988). Simulated data clearly indicated that postruminal mixing pools increased the order of gamma function in the age-dependent compartment compared with the models that best described passage kinetics from the reticulorumen (Huhtanen et al., 2006a). Owing to the mixing effects in postruminal compartments, the maximum PEG concentrations occurred a few hours after the first appearance in feces (Figure 6). Markers flow through the small intestine and colon in a laminar manner and the time elapsed between marker administration into the rumen and the first appearance in feces represents TD in the intestines (Huhtanen and Kukkonen, 1995).

In the current study, PEG concentrations in feces started to increase at around $6 \mathrm{~h}$ postdose and reached the maximum concentrations at approximately $12 \mathrm{~h}$. Therefore, when PEG is administered twice daily, the maximum concentrations occur at approximately 12 -h intervals with $6 \mathrm{~h}$ between the minimum and the maximum (Figure 7). The practical implications of these findings are that the sampling protocol should cover the 6-h period between extreme concentrations or the frequency of PEG administration should be increased to alleviate the diurnal variation in marker concentrations. As demonstrated by the simulations, dividing the daily PEG dose into 3 equal doses resulted in considerably smaller variation around the daily mean concentration than twice-daily administration (Figure 7).

Diurnal variation in fecal marker concentrations may be decreased by increased frequency of marker admin- istration (Prigge et al., 1981). Prigge et al. (1981) demonstrated that, in an ideal case, fecal output could be accurately determined by once-daily dosing of a marker and collecting fecal spot samples once daily. In practice, sampling schemes relying only 1 or a few samples collected at a fixed time of the day are prone to large errors owing to large diurnal variation in fecal marker concentrations and the fact that the optimal sampling time may be altered when large changes in feed intake alter the marker residence time in the rumen and the remaining digestive tract.

An alternative means to decrease large diurnal variation in marker concentrations is to use insoluble markers that have considerably slower passage rate than soluble markers (Udén et al., 1980; Snyder et al., 1984). Early comparisons between chromium sesquioxide and PEG indicated that particulate associated marker exhibited considerably more stable fecal concentrations than soluble marker (Corbett et al., 1958). This was confirmed in a study (Delagarde et al., 2010) conducted using dairy cows in mid lactation and offered either a restricted $(127 \mathrm{~g} / \mathrm{kg}$ of metabolic BW) or ad libitum diet $(177 \mathrm{~g} / \mathrm{kg}$ of metabolic BW). In that study, the variation within day was considerably smaller than in the current study, ranging between 0.86 and 1.13 of the mean for $\mathrm{Cr}$ and 0.88 to 1.12 for $\mathrm{Yb}$.

The range in simulated PEG concentrations was slightly smaller than that observed in the current experiment. One explanation for this difference is that the model assumed fecal output occurred at a constant rate, whereas fecal DM output does not remain constant due to diurnal variation. In our previous study (L. Nyholm and S. Ahvenjärvi, unpublished observations), 5 dairy cows were offered diets similar to the current study over 2 experimental periods. Cows defecated 9.2 times between 0600 and $1800 \mathrm{~h}$ and 10.8 times between 1800 and $0600 \mathrm{~h}$. The proportion of feces excreted between 0600 and $1800 \mathrm{~h}$ was 0.46 and between 1800 and $0600 \mathrm{~h} 0.54$ of daily fecal output. These observations indicate a tendency for differences between the diurnal and nocturnal pattern of fecal excretion, but in lactating dairy cows allowed free access to feed these differences are not very large.

\section{Between-Cow Variation in Digestibility}

In the current study, the digestibility of both diets was accurately estimated using PEG but the precision in terms of cow-specific digestibility coefficients was not adequate. This is clearly evidenced by the poor correlation between DM digestibility measured by total collection and that estimated using PEG $(\mathrm{r}=-0.17)$ or iNDF $(R=0.44)$. Significant differences between animals in diet DM digestibility indicate that some cows 
digested feed more efficiently than others; nonetheless, the range in DM digestibility was only 0.02 units. Assuming the mean DMI measured in the current study $(26.0 \mathrm{~kg} / \mathrm{d}), 0.02$ units of difference in digestibility equals to $0.5 \mathrm{~kg} / \mathrm{d}$ of $\mathrm{DM}$ of feces. If DMI would be estimated based on fecal output and using the mean digestibility determined for the group of cows consuming the same diet, then the difference between the mean and range was 0.01 units and the true DMI was either overestimated by $0.9 \mathrm{~kg} / \mathrm{d}$ or underestimated by 0.8 $\mathrm{kg} / \mathrm{d}$. These estimates are consistent with SEP for the regression equation used to predict DMI from fecal DM output estimates using PEG ( $\mathrm{SEP}=0.85 \mathrm{~kg} / \mathrm{d})$.

The relationship between measured DMI and that estimated using PEG and iNDF $\left(\mathrm{SEP}=0.86 \mathrm{~kg} / \mathrm{d}, \mathrm{R}^{2}\right.$ $=0.81$ ) indicated that DMI could be predicted fairly accurately using the same DM digestibility for all cows consuming the same diet. Using PEG to estimate daily fecal output decreased the accuracy of DMI predictions only slightly compared with much more laborious total fecal collection $\left(\mathrm{SEP}=0.80 \mathrm{~kg} / \mathrm{d}, \mathrm{R}^{2}=0.83\right)$. These findings are consistent with small between-cow differences in DM digestibility observed in the current study. These findings also demonstrate that cow-specific digestibilities must be determined with high precision and accuracy to improve DMI predictions over those based on group-specific digestibilities. In the current study, iNDF was chosen as an internal marker because it could be determined using NIRS (Nousiainen et al., 2004; Mehtiö et al., 2016) so as to allow simultaneous and cost-effective analysis of PEG and iNDF concentrations in feces. Currently, iNDF concentrations in feed rations must be predicted based on individual ingredients because NIRS equations have not been developed for total rations. Possibly, alternative internal markers (e.g., acid-insoluble ash; Van Keulen and Young, 1977) could have provided more precise estimates of cowspecific digestibility, but without the potential to be analyzed using NIRS.

Poor precision of cow-specific digestibility measurements decreased the precision of DMI predictions compared with group-specific digestibility coefficients. Previous studies have suggested that differences between individual cows $(\mathrm{n}=44)$ in OM digestibility are small (SD 0.0123, mean 0.724; Mehtiö et al., 2016), but the feeding level and diet composition may have substantial effects on OM digestibility (Tyrrell and Moe, 1975; Colucci et al., 1982). Diet DM digestibility decreased by 0.063 units for a low-forage diet when DMI increased from 12 to $42 \mathrm{~g} / \mathrm{kg}$ of $\mathrm{BW}$ and by 0.032 units for a high-forage diet when DMI increased from 13 to $32 \mathrm{~g} /$ $\mathrm{kg}$ of BW (Colucci et al., 1982). These observations indicate that the same digestibility could be assumed for a group of cows, provided that animals are consum- ing the same diet at similar level of DMI or at similar stage of lactation (Mehtiö et al., 2016).

\section{CONCLUSIONS}

The current findings indicate that PEG administered into the rumen of dairy cows was completely recovered in feces and, thus, fecal output was accurately estimated using PEG. A close relationship between DMI and fecal output estimated using PEG indicates good potential to predict feed intake using PEG. The precision of cow-specific digestibility estimates based on iNDF was not adequate for satisfactory predictions of DMI. Small differences between cows in DM digestibility suggested that the same digestibility could be used for a group of cows to predict DMI with sufficient accuracy. In practice, fecal DM output could be determined for individual cows using PEG, whereas groupspecific DM digestibility could be determined for a few cows representative of a group consuming the same diet at similar feeding level. The current study indicated that, to overcome inherent day-to-day variation in feed intake and fecal output, the minimum of 4 fecal spot samples should be collected over $4 \mathrm{~d}$. Preferably, these samples should be distributed evenly over the 12 -h marker administration interval to compensate for the circadian variation in fecal PEG concentrations.

\section{ACKNOWLEDGMENTS}

This study was funded by Finnish Ministry of Agriculture (DNRO: 1844/312/2012); Valio Oy, Helsinki, Finland; Faba co-op, Hollola, Finland; Suomen Naudanjalostussäätiö, Hamina, Finland; and RAISIOagro Ltd., Raisio, Finland.

\section{REFERENCES}

Ahvenjärvi, S., E. Joki-Tokola, A. Vanhatalo, S. Jaakkola, and P. Huhtanen. 2006. Effects of replacing grass silage with barley silage in dairy cow diets. J. Dairy Sci. 89:1678-1687.

Andueza, D., F. Picard, J. Aufrère, J. Jamot, G. Bechet, and R. Baumont. 2013. Polyethylene glycol determined by near-infrared reflectance spectroscopy to estimate faecal output in sheep fed fresh permanent grassland forage. Livest. Sci. 155:38-43. https://doi .org/10.1016/j.livsci.2013.03.022.

AOAC International. 2012. Official Methods of Analysis. 19th ed. AOAC International, Gaithersburg, MD.

Arrieta, M. C., L. Bistritz, and J. B. Meddings. 2006. Alterations in intestinal permeability. Gut 55:1512-1520. https://doi.org/10 .1136 /gut.2005.085373.

Bjarnason, I., A. MacPherson, and D. Hollander. 1995. Intestinal permeability: An overview. Gastroenterology 108:1566-1581.

Casasús, I., and E. Albanell. 2014. Prediction of faecal output and hay intake by cattle from NIRS estimates of faecal concentrations of orally-dosed polyethylene glycol. Anim. Feed Sci. Technol. 192:4861. https://doi.org/10.1016/j.anifeedsci.2014.04.002.

Casasús, I., A. Sanz, D. Villalba, R. Ferrer, and R. Revilla. 2004. Intake capacity of two breeds of suckler cattle of different milk 
yield potential and validation of prediction models. Livest. Prod. Sci. 89:195-207. https://doi.org/10.1016/j.livprodsci.2004.02.003.

Colucci, P. E., L. E. Chase, and P. J. Van Soest. 1982. Feed intake, apparent diet digestibility, and rate of particulate passage in dairy cattle. J. Dairy Sci. 65:1445-1456.

Corbett, J. L., J. F. D. Greenhalgh, P. E. Gwynn, and D. Walker. 1958. Excretion of chromium sesquioxide and polyethyleneglycol by dairy cows. Br. J. Nutr. 12:266-276.

Decruyenaere, V., E. Froidmont, N. Bartiaux-Thill, A. Buldgen, and D. Stilmant. 2012. Faecal near-infrared reflectance spectroscopy (NIRS) compared with other techniques for estimating the in vivo digestibility and dry matter intake of lactating grazing dairy cows. Anim. Feed Sci. Technol. 173:220-234. https://doi.org/10.1016/j .anifeedsci.2012.02.005

Delagarde, R., E. Pérez-Ramírez, and J. L. Peyraud. 2010. Ytterbium oxide has the same accuracy as chromic oxide for estimating variations of faecal dry matter output in dairy cows fed a total mixed ration at two feeding levels. Anim. Feed Sci. Technol. 161:121-131. https://doi.org/10.1016/j.anifeedsci.2010.08.006.

Finnish Act on the Use of Animals for Experimental Purposes. 2013 Accessed Feb. 14, 2018. https://www.finlex.fi/fi/laki/alkup/2013/ 20130497.

Hassoun, P., G. Viudes, P. Autran, D. Bastianelli, and F. Bocquier. 2013. A method for estimating dry forage intake by sheep using polyethylene glycol as a faecal marker measured with NIRS. Animal 7:1280-1288. https://doi.org/10.1017/S1751731113000323.

Holloway, J. W., R. E. Estell II, and W. T. Butts Jr. 1981. Relationship between fecal components and forage consumption and digestibility. J. Anim. Sci. 52:836-848.

Hopson, D. E., and J. E. McCroskey. 1972. Influence of dose level and method of administration on the use of polyethylene glycol for determining fecal output of cattle. J. Anim. Sci. 35:1054-1057.

Huhtanen, P., S. Ahvenjärvi, M. R. Weisbjerg, and P. Nørgaard. 2006a. Digestion and passage of fibre in ruminants. Pages 87-135 in Ruminant Physiology: Digestion, Metabolism and Impact of Nutrition on Gene Expression, Immunology and Stress. K. Sejrsen, T. Hvelplund and M. O. Nielsen, ed. Wageningen Press, Wageningen, the Netherlands.

Huhtanen, P., and U. Kukkonen. 1995. Comparison of methods, markers, sampling sites and models for estimating digesta passage kinetics in cattle fed at two levels of intake. Anim. Feed Sci. Technol. $52: 141-158$.

Huhtanen, P., J. Nousiainen, and M. Rinne. 2006b. Recent developments in forage evaluation with special reference to practical applications. Agric. Food Sci. 15:293-323.

Huhtanen, P. J., R. Blauwiekel, and I. Saastamoinen. 1998. Effects of intraruminal infusions of propionate and butyrate with two different protein supplements on milk production and blood metabolites in dairy cows receiving grass silage-based diet. J. Sci. Food Agric. $77: 213-222$.

Huida, L., H. Väätäinen, and M. Lampila. 1986. Comparison of dry matter contents in grass silages as determined by oven drying and gas chromatographic water analysis. Annales Agriculturae Fenniae $25: 215-230$.

Kane, E. A., W. C. Jacobson, and L. A. Moore. 1950. A comparison of techniques used in digestibility studies with dairy cattle. J. Nutr. 41:583-596.

Kotb, A. R., and T. D. Luckey. 1972. Markers in nutrition. Nutr. Abstr. Rev. 42:813-845.

Krämer, M., P. Lund, and M. R. Weisbjerg. 2013. Rumen passage kinetics of forage- and concentrate-derived fiber in dairy cows. J. Dairy Sci. 96:3163-3176. https://doi.org/10.3168/jds.2012-6146.
Kuoppala, K., M. Rinne, S. Ahvenjärvi, J. Nousiainen, and P. Huhtanen. 2010. The effect of harvesting strategy of grass silage on digestion and nutrient supply in dairy cows. J. Dairy Sci. 93:32533263. https://doi.org/10.3168/jds.2009-3013.

Landau, S., S. Friedman, L. Devash, and S. J. Mabjeesh. 2002. Polyethylene glycol, determined by near-infrared reflectance spectroscopy, as a marker of fecal output in goats. J. Agric. Food Chem. 50:1374-1378.

Lippke, H. 2002. Estimation of forage intake by ruminants on pasture. Crop Sci. 42:869-872.

Mayes, R. W. C. S. Lamb, and P. M. Colgrove. 1986. The use of dosed and herbage n-alkanes as markers for the determination of herbage intake. J. Agric. Sci. Camb. 107:161-170.

Mehtiö, T., M. Rinne, L. Nyholm, P. Mäntysaari, A. Sairanen, E. A. Mäntysaari, T. Pitkänen, and M. H. Lidauer. 2016. Cow-specific diet digestibility predictions based on near-infrared reflectance spectroscopy scans of faecal samples. J. Anim. Breed. Genet. 133:115-125. https://doi.org/10.1111/jbg.12183.

Moore, J. A., K. R. Pond, M. H. Poore, and T. G. Goodwin. 1992. Influence of model and marker on digesta kinetic estimates for sheep. J. Anim. Sci. 70:3528-3540.

Nousiainen, J., S. Ahvenjärvi, M. Rinne, M. Hellämäki, and P. Huhtanen. 2004. Prediction of indigestible cell wall fraction of grass silage by near infrared reflectance spectroscopy. Anim. Feed Sci. Technol. 115:295-311. https://doi.org/10.1016/j.anifeedsci 2004.03.004.

Nousiainen, J., M. Rinne, M. Hellämäki, and P. Huhtanen. 2003. Prediction of the digestibility of the primary growth of grass silages harvested at different stages of maturity from chemical composition and pepsin-cellulase solubility. Anim. Feed Sci. Technol 103:97-111.

Pond, K. R., W. C. Ellis, J. H. Matis, H. M. Ferreiro, and J. D. Sutton. 1988. Compartment models for estimating attributes of digesta flow in cattle. Br. J. Nutr. 60:571-595.

Prigge, E. C., G. A. Varga, J. L. Vicini, and R. L. Reid. 1981. Comparison of ytterbium chloride and chromium sesquioxide as fecal indicators. J. Anim. Sci. 53:1629-1633.

Shaffer, C. B., and F. H. Critchfield. 1947. The absorption and excretion of the solid polyethylene glycols ("Carbowax" compounds). J. Am. Pharm. Assoc. Pharm. Assoc. 36:152-157.

Snyder, T. J., L. D. Muller, J. A. Rogers, and S. M. Abrams. 1984. Digesta passage measured by markers in dairy cows fed two ratios of corn silage:grain with 0 or $1.2 \%$ sodium bicarbonate. J. Dairy Sci. 67:1953-1964.

Sperber, I., S. Hydén, and J. Ekman. 1953. The use of polyethylene glycol as a reference substance in the study of ruminant digestion. Kungliga Lantbrukhögskolans Annaler 20:337-344.

Tyrrell, H. F., and P. W. Moe. 1975. Effect of intake on digestive efficiency. J. Dairy Sci. 58:1151-1163.

Udén, P., P. E. Colucci, and P. J. Van Soest. 1980. Investigation of chromium, cerium and cobalt as markers in digesta. Rate of passage studies. J. Sci. Food Agric. 31:625-632.

Van Keulen, J., and B. A. Young. 1977. Evaluation of acid insoluble ash as a natural marker in ruminant digestibility studies. J. Anim. Sci. 44:282-287.

Van Soest, P. J., J. B. Robertson, and B. A. Lewis. 1991. Methods for dietary fiber, neutral detergent fiber, and nonstarch polysaccharides in relation to animal nutrition. J. Dairy Sci. 74:3583-3597. 